\title{
Clinical and patient-reported outcomes in oncoplastic breast conservation surgery from a single surgeon's practice in a busy community hospital in Canada
}

\author{
Ashley DiPasquale, MD \\ Zosia Prus-Czarnecka, MD \\ Lindsay Delmar, MD \\ Lashan Peiris, MBBS
}

Accepted February 4, 2021

\section{Correspondence to:}

A. DiPasquale

Faculty of Medicine and Dentistry

University of Alberta

2D, Walter C Mackenzie Health Sciences

Centre

$8440-112 \mathrm{St}$

Edmonton AB T6G 2R7

adipasqu@ualberta.ca

Cite as: Can J Surg 2022 February 8; 65(1). doi:10.1503/cjs.019120
Background: Oncoplastic breast surgery aims to maintain quality of life by pre-empting and mitigating against breast asymmetry while not compromising oncological effectiveness. This case series demonstrates the implementation of an effective oncoplastic surgical practice in a community hospital within Canada and shows low rates of perioperative complications as well as high levels of patient-reported outcome measures.

Methods: A retrospective chart review of patients diagnosed with stage $0-3$ breast cancer treated with level I and level II oncoplastic techniques by a single breast surgeon was undertaken. Patient, tumour, procedure, and outcome data were collected. Patient satisfaction was assessed with the Breast-Q questionnaire administered pre- and postoperatively.

Results: Oncoplastic breast conservation surgery was performed on 340 patients over a 31 -month period. The average size of breast lesions was $1.8 \mathrm{~cm}$, with 96 patients having lesions $2-5 \mathrm{~cm}$ in size and 10 patients having tumours larger than $5 \mathrm{~cm}$. Thirty $(8.8 \%)$ patients experienced a complication requiring intervention. The positive margin rate was $9.4 \%$, and the completion mastectomy rate was $4.7 \%$. Breast Q scores increased across breast satisfaction, process of care, psychosocial, physical, and sexual satisfaction domains postoperatively.

Conclusion: This case series demonstrates the feasibility of an oncoplastic breast surgery practice in a busy community hospital in Canada. This adds to the growing body of North American data on the clinical and oncological safety of these techniques and introduces the idea of collecting patient-reported outcome measures within a Canadian population. We hope that this enables these techniques to become the standard of care in North America.

Contexte : La chirurgie mammaire oncoplastique vise le maintien de la qualité de vie en prévenant et en atténuant l'asymétrie mammaire sans nuire à l'efficacité oncologique. La présente étude d'une série de cas porte sur l'implantation d'une pratique efficace de chirurgie oncoplastique dans un hôpital communautaire canadien. Elle montre une faible incidence de complications périopératoires ainsi qu'un effet positif sur les mesures des résultats déclarés par les patientes.

Méthodes : Nous avons procédé à un examen rétrospectif des dossiers de patientes ayant un diagnostic de cancer du sein de stade 0 à 3 et traitées au moyen de techniques oncoplastiques de niveau I et II appliquées par un même chirurgien. Les données sur la patiente, la tumeur, la procédure et les résultats ont été collectées. La satisfaction de la patiente a été mesurée à l'aide du questionnaire Breast-Q, rempli avant et après l'opération.

Résultats : Une chirurgie oncoplastique conservatrice du sein a été réalisée sur 340 patientes sur une période de 31 mois. La taille moyenne des lésions mammaires était de 1,8 cm; 96 patientes avaient une lésion de $2-5 \mathrm{~cm}$, et 10 patientes avaient une tumeur de plus de $5 \mathrm{~cm}$. En tout, 30 patientes (8,8\%) ont développé des complications nécessitant une intervention. Le taux de marge positive était de $9,4 \%$, et le taux de mastectomie totale était de 4,7\%. Les résultats du questionnaire Breast-Q ont montré une hausse de la satisfaction relativement aux seins, au processus de soins et aux aspects psychosocial, physique et sexuel après la chirurgie.

Conclusion : Cette étude démontre la faisabilité du recours à la chirurgie mammaire oncoplastique dans un hôpital communautaire achalandé du Canada. Elle vient enrichir le corpus grandissant de données nord-américaines sur le caractère sécuritaire de ces techniques sur les plans clinique et oncologique, et met en avant l'idée de recueillir les mesures des résultats déclarés par les patients au sein d'une population canadienne. Nous espérons que ces travaux faciliteront l'adoption de ces techniques comme pratique standard en Amérique du Nord. 
$\mathbf{T}$ he term "oncoplastic surgery" first originated in the 1990s. Although there are various - sometimes contradictory - definitions in the literature, oncoplastic breast surgery (OPBS) generally requires a combination of oncological and plastic surgical techniques. ${ }^{1}$ The American Society of Breast Surgeons defines OPBS as "oncologic partial mastectomy with ipsilateral defect repair using volume displacement and volume replacement techniques with contralateral symmetry surgery as appropriate."'

The overriding ethos of oncoplastic breast conservation surgery is to maintain a woman's quality of life and obtain an acceptable breast appearance while not compromising oncological effectiveness. The new generation of breast surgeon, therefore, should be trained to provide a wide-ranging OPBS practice and, ideally, to offer a service in total breast reconstruction.

There are many benefits to oncoplastic procedures. OPBS allows for wide excision - perhaps avoiding a mastectomy - without sacrificing oncological outcomes. ${ }^{3,4}$ Furthermore, data suggest that cosmetic outcomes after OPBS are superior to skin- or nipple-sparing mastectomy with immediate breast reconstruction..$^{5,6}$ Oncoplastic excisions also require less extensive reconstructive surgery and carry a risk of fewer complications than total mastectomy with immediate or delayed breast reconstruction. ${ }^{5}$

In addition to these benefits, the literature would suggest that local recurrence rates, overall survival and disease-free survival are similar after OPBS and traditional breast cancer surgery, with local recurrence rates ranging from $0 \%$ to $9.4 \% .3,4,7,8$ The rate of margin involvement is also similar in patients treated with only wide-local excision. ${ }^{9,10}$

Oncoplastic breast surgery is the mainstay of breast cancer surgery in Europe. Furthermore, patients in most European countries benefit from seeing a breast surgeon who can offer both oncoplastic breast conservation surgery as well as total breast reconstruction. Oncoplastic units and oncoplastic centres, where both oncoplastic breast surgeons and plastic surgeons work side by side to offer the full range of oncological and reconstructive procedures, are now commonplace. The evolution of subspecialist training in breast surgery as well as the publication of national oncoplastic guidelines in several European countries have helped to define a new era in breast surgery service provision at a national level. ${ }^{11}$ The UK National Mastectomy and Reconstruction Audit provided a national snapshot of reconstructive practices in the UK suggesting an immediate breast reconstruction (IBR) rate of $21 \% .{ }^{12}$ There are no contemporary data confirming the current IBR rate in Canada, but previous national studies have suggested a figure as low as $7 \%$, and regional studies reported rates of $4 \%-14 \% .{ }^{13-15}$ A close working relationship between general surgery and plastic surgery services remains vital when offering patients their surgery of choice; therefore, maintaining a low threshold for inter-specialty referral, particularly for patients requiring complex reconstructive procedures, remains key. Our series shows that the majority of patients requiring a completion mastectomy owing to ongoing positive margins after attempted oncoplastic breast conservation can undergo IBR performed by the same oncoplastic breast surgeon without the need for coordination with a second surgeon. Those opting for microvascular free-flap reconstruction and patients with complex pre-existing cosmetic issues (e.g., tuberous breast deformity) continue to benefit from interspecialty referral between general surgery and plastic surgery, and this remains fundamental to offering the right reconstruction to the right patient at the right time, resulting in the best possible outcomes and patient satisfaction.

The evidence around the effectiveness of oncoplastic and reconstructive breast surgery continues to grow. Oncoplastic procedures and immediate breast reconstructions, however, are more complex, carry a higher risk of perioperative complications and involve longer operating times. The need for a surgeon who has dedicated oncoplastic training is one of a number of factors that have been shown previously to deter Canadian centres from performing OPBS. ${ }^{16}$

The aim of this study was to highlight the effectiveness of an OPBS practice in a busy community hospital setting in Alberta, Canada, by analyzing both clinical outcomes and patient-reported outcomes over a prolonged period of follow-up.

\section{Methods}

\section{Study participants}

A retrospective chart review was performed of patients diagnosed with stage $0-3$ breast cancer who were treated with level I and level II oncoplastic techniques. Patients were treated at a single community centre by a single breast surgeon over a 31-month period between 2017 and 2019.

\section{Clinical-pathological parameters}

Patient demographics, tumour characteristics, procedure types, and clinical outcomes were collected from electronic medical records. Outcome variables included margin status, completion mastectomy rate, and complication rates. The need for contralateral balancing procedures was also recorded. Oncoplastic procedures were classified as per the American Society of Breast Surgeons consensus definition and classification system of oncoplastic surgery. ${ }^{2}$

The margin status of patients undergoing a margin revision was updated at the time of data collection to reflect the current American Society of Breast Surgeon consensus 
guidelines. ${ }^{17}$ Margins were considered positive if invasive disease or ductal carcinoma in situ (DCIS) was found at ink for mixed in situ/invasive lesions, or if DCIS was found within $2 \mathrm{~mm}$ of the margin in patients with DCIS only.

\section{Patient satisfaction outcomes}

Patients consenting to level II OPBS were given the BreastQ Breast Conserving Therapy module preoperatively (as a baseline assessment of quality of life), at 3 months postoperatively and again at 9 months postoperatively. Patients who subsequently underwent a completion mastectomy were excluded from the BreastQ analysis. Scores range from 0 to 100 , with higher scores correlating with greater patient satisfaction. Questionnaires were scored using the scoring instructions of the BreastQ User Manual version 2.0. ${ }^{18}$ Data collection is ongoing as part of a prospective database to assess patient satisfaction.

\section{Statistical analysis}

Descriptive statistics were used to analyze variables of interest. Means were calculated for continuous variables and proportions for categorical variables. Paired $t$ tests were used to analyze BreastQ scores. We considered results to be significant at $p<0.05$. We used Stata statistical software, version 15 for statistical analysis.

\section{Results}

\section{Patient and tumour characteristics}

A total of 340 patients met our inclusion criteria. Patient and tumour characteristics are reported in Table 1 . The mean age of patients was 60 years. Patients went home on the same day of surgery $95 \%$ of the time. The body mass index (BMI) of patients ranged from healthy weight to morbidly obese (range 18-50), with the majority of patients having an overweight BMI of 25-30 (29.7\%). Twenty-nine patients $(8.5 \%)$ were diabetic, and 47 $(13.8 \%)$ were current smokers. Close to half of patients (47.7\%) had a C-cup breast.

Tumour characteristics varied (Table 1). The average size of breast lesions was $1.8 \mathrm{~cm}$, with 96 patients having lesions $2-5 \mathrm{~cm}$ in size, and 10 patients having tumours larger than $5 \mathrm{~cm}$. The majority of lesions (47.1\%) were located in the upper outer quadrant. Invasive ductal carcinoma was the most common pathology, with 43 (12.7\%) patients diagnosed with in situ disease only. More than half of patients presented with early stage 1 disease, and grade 2 was the most common grade of disease. Patients were most often estrogen receptor-/progesterone receptor-positive and human epidermal growth factor receptor 2 (HER2)-negative.

\section{Oncoplastic procedure}

Level I oncoplastic procedures were used in 228 (67.1\%) patients. The remaining patients underwent level II oncoplastic procedures, including 32 Benelli round blocks, 23 Wise pattern therapeutic mammoplasties, 4 pedicled myocutaneous latissimus dorsi "mini-flaps," and a combination of advancement flaps, non-Wise pattern mammoplasties, therapeutic mastopexies, and Grisotti flaps (Figure 1 and Figure 2).

Sentinel lymph node biopsy (SLNB) was the most common form of axillary surgery, with 264 patients receiving SLNB alone (Table 2).

A contralateral procedure was performed in 31 $(9.1 \%)$ patients. These procedures included reduction mammoplasties, contralateral mastopexies, and implant augmentation after the patient received a completion mastectomy with immediate breast reconstruction (Table 2).

\section{Clinical outcomes}

Margin revision occurred in 74 patients (Table 3). The overall revision rate was $21.8 \%$. This revision rate decreased to $18 \%$ after updated American Society for Radiation Oncology/Society of Surgical Oncology (ASTRO/SSO) consensus margin recommendations were implemented in late 2018.

On review of the margin data within the cohort, taking into account the recent margin consensus guidelines, only $32(9.4 \%)$ patients who had margin revisions would have been considered to have positive margins under the updated guidelines (Table 3).

A completion mastectomy was performed in 16 (4.7\%) of these patients, making the final breast preservation rate $95.3 \%$. At the time of completion mastectomy, 5 of these patients received immediate sub- or prepectoral implant reconstruction and 1 patient received a tissue expanderassisted latissimus dorsi reconstruction, all performed by the same surgeon. Two patients opted for delayed reconstruction with a deep inferior epigastric perforators (DIEP) flap performed by a local plastic surgeon.

Complications requiring intervention occurred in $30(8.8 \%)$ patients and included hematomas, seromas and surgical site (SSI)/wound infections (Table 4).

\section{Patient satisfaction}

The BreastQ Breast Conserving Therapy module was completed by 39 patients preoperatively, by 27 patients 3 months postoperatively and by 17 patients 9 months postoperatively; 25 patients completed both a preoperative and the 3-month postoperative questionnaire, and 13 patients had completed all 3 questionnaires at the time of analysis. Patients completing the BreastQ had 


\begin{tabular}{|c|c|}
\hline Characteristic & No. $(\%)^{*}$ \\
\hline Age, mean \pm SD (range), yr & $60 \pm 0.7(23-89)$ \\
\hline \multicolumn{2}{|l|}{ BMI } \\
\hline $18-24$ & $86(25.3)$ \\
\hline $25-29$ & $101(29.7)$ \\
\hline $30-34$ & $91(26.8)$ \\
\hline $35-39$ & $42(12.4)$ \\
\hline$\geq 40$ & $18(5.3)$ \\
\hline Diabetes & $29(8.5)$ \\
\hline Current smoker & $47(13.8)$ \\
\hline \multicolumn{2}{|l|}{ Breast cup size } \\
\hline A & $27(7.7)$ \\
\hline B & $11(3.2)$ \\
\hline C & $162(47.7)$ \\
\hline D & 97 (28.5) \\
\hline$\geq \mathrm{DD}$ & $43(12.7)$ \\
\hline Tumour size, mean \pm SD (range), cm & $1.8 \pm 0.1(0.4-7.0)$ \\
\hline \multicolumn{2}{|l|}{ Tumour size, $\mathrm{cm}$} \\
\hline$<2$ & $234(68.8)$ \\
\hline $2-5$ & $96(28.2)$ \\
\hline$>5$ & $10(2.9)$ \\
\hline \multicolumn{2}{|l|}{ Tumour location } \\
\hline UOO & $160(47.1)$ \\
\hline LOQ & $52(15.3)$ \\
\hline UIO & $35(10.3)$ \\
\hline LIO & $60(17.7)$ \\
\hline Central & $27(7.9)$ \\
\hline Multi-quadrant & $8(1.8)$ \\
\hline \multicolumn{2}{|l|}{ Tumour histology } \\
\hline IDC & $262(77.1)$ \\
\hline ILC & $19(5.6)$ \\
\hline Mixed & $5(1.5)$ \\
\hline In situ disease only & $43(12.7)$ \\
\hline Other & $12(3.5)$ \\
\hline \multicolumn{2}{|l|}{ Stage } \\
\hline $1 \mathrm{~A}$ & $164(48.2)$ \\
\hline 1B & $22(6.5)$ \\
\hline $2 \mathrm{~A}$ & $63(18.5)$ \\
\hline $2 \mathrm{~B}$ & $27(7.9)$ \\
\hline $3 \mathrm{~A}$ & $12(3.5)$ \\
\hline $3 \mathrm{~B}$ & $1(0.3)$ \\
\hline $3 C$ & $1(0.3)$ \\
\hline \multicolumn{2}{|l|}{ Grade } \\
\hline 1 & 74 (21.8) \\
\hline 2 & $147(43.2)$ \\
\hline 3 & 115 (33.8) \\
\hline \multicolumn{2}{|l|}{ Hormone receptor status } \\
\hline ER/PR positive & 265 (77.9) \\
\hline ER positive/PR negative & 37 (10.9) \\
\hline ER/PR negative & $31(9.1)$ \\
\hline \multicolumn{2}{|l|}{ HER2 status } \\
\hline HER2 positive & $27(7.9)$ \\
\hline HER2 negative & 273 (80.3) \\
\hline \multicolumn{2}{|c|}{$\begin{array}{l}\mathrm{BMI}=\text { body mass index; } \mathrm{ER}=\text { estrogen receptor; } \mathrm{HER} 2=\text { human epidermal growth } \\
\text { factor receptor } 2 ; \mathrm{IDC}=\text { invasive ductal carcinoma; } \mathrm{ILC}=\text { invasive lobular carcinoma; } \\
\mathrm{LIQ}=\text { lower inner quadrant; } \mathrm{LOQ}=\text { lower outer quadrant; } \mathrm{PR}=\text { progesterone receptor; } \\
\mathrm{SD}=\text { standard deviation; } \mathrm{UIQ}=\text { upper inner quadrant; } \mathrm{UOQ}=\text { upper outer quadrant. } \\
\text { *Unless indicated otherwise. }\end{array}$} \\
\hline
\end{tabular}

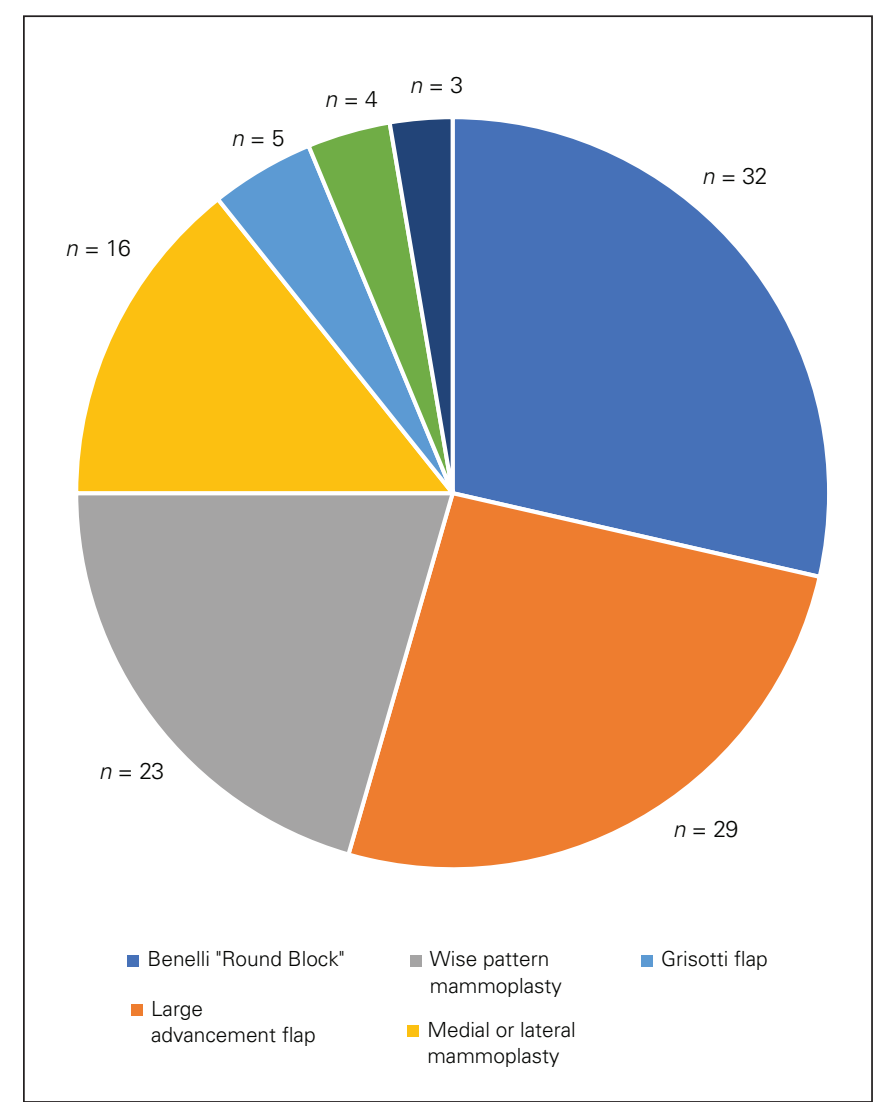

Fig. 1. Number (\%) of level II oncoplastic procedures performed during the study period.

tumours that ranged from T1 to T3 in size, and they all received level II oncoplastic procedures.

Average BreastQ scores for breast satisfaction and process of care as well as sexual, psychosocial and physical well-being increased postoperatively compared with preoperative scores and remained elevated 9 months postoperatively (Figure 3). At 3 months postsurgery, the elevation in mean scores for psychosocial and physical well-being were significant, with a difference of $10.3(p=0.014)$ and 11.3 ( $p=0.024$ ), respectively (Figure 4). At 9 months postsurgery, the elevation in mean scores for psychosocial wellbeing remained significant compared with preoperative scores, with a difference of $15.4(p=0.005$; Figure 5). Physical well-being scores pertaining to the chest wall decreased 9 months postoperatively compared with scores at 3 months postoperatively, but remained higher overall than the baseline scores (Figure 3).

\section{Discussion}

This case series is, to our knowledge, the largest of its kind in Canada showing the feasibility of an OPBS practice in a busy community hospital. This adds to the growing body of North American data on the clinical safety of these techniques. Our study also shows 


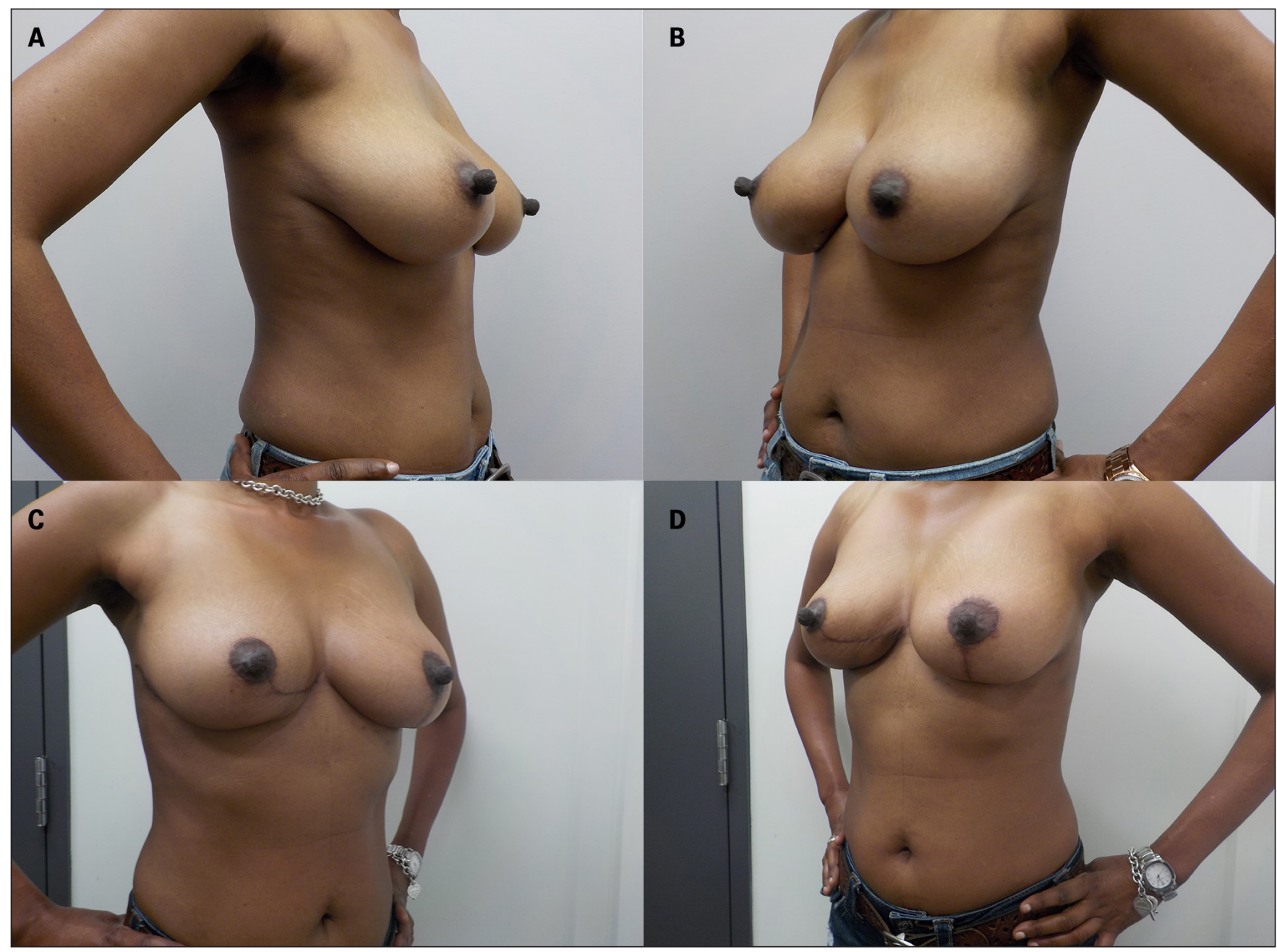

Fig 2. (A, B) Pre- and (C, D) 4-months postoperative images of a 44-year-old woman with right lower-inner quadrant multifocal grade 2 ductal carcinoma in situ (DCIS) who underwent oncoplastic right V-mammoplasty with left breast reduction mammoplasty for symmetry. The patient's pathology report indicated a high-grade DCIS $>9 \mathrm{~cm}$, with a maximum focus diameter of $58 \mathrm{~mm}$. The tumour was estrogen- and progesterone-receptor-positive and human epidermal growth factor receptor 2 (HER2)-negative. It was staged as pT3pN1 (stage 3a). We achieved margins of $1.5 \mathrm{~mm}$ for her DCIS and $7 \mathrm{~mm}$ for the invasive portions in the specimen.

\section{Table 2. Surgical procedures performed}

\begin{tabular}{|lc|}
\hline Axillary surgery & No. $(\%)$ \\
\hline SLNB & $264(77.7)$ \\
\hline ALND & $18(5.3)$ \\
\hline SLNB with completion ALND & $8(2.6)$ \\
\hline None & $50(14.7)$ \\
\hline Contralateral procedure & $31(9.1)$ \\
\hline Reduction mammoplasty & $23(74.2)$ \\
\hline Mastopexy & $2(6.5)$ \\
\hline Implant augmentation & $1(3.2)$ \\
\hline ALND = axillary lymph node dissection; SLNB = sentinel lymph node biopsy. \\
\hline
\end{tabular}

that patient-reported outcomes are not compromised when oncoplastic techniques are used; in fact, despite the devastating diagnosis of breast cancer, patient scores for psychosocial and physical well-being can improve significantly in the longer term after this type of surgery.
Owing to the larger excisions and area of dissection involved with oncoplastic resections, complication rates are expected to be higher than those in patients undergoing conventional breast-conservation surgery. Our series confirms an overall infection rate of $13 \%$ and a postoperative hematoma rate of $3.3 \%$, which compares favourably with published literature. Knowles and colleagues reported an infection rate of $13.1 \%$ and hematoma rate of $8.7 \%{ }^{4}$ Vitug and Newman reported an infection rate of $3.4 \%-18.3 \%$ and a hematoma rate of $2 \%-10 \% .{ }^{19}$ In our series, the complication rate in patients receiving level II oncoplastic procedures was $8.8 \%$. One systematic review reported that postoperative complications, including liponecrosis, skin necrosis, hematoma, seroma, delayed wound healing, nipple necrosis, and/or infection, occurred in $14.3 \%$ of patients receiving OPBS. ${ }^{20}$

As breast cancer prognosis continues to improve, the main priority of breast cancer surgery is improving oncological outcomes. With women living longer after their 


\section{Table 3. Margin status and completion mastectomies}

\begin{tabular}{|lc|}
\hline Outcomes & No. (\%) \\
\hline Total margin revisions & $74(21.8)$ \\
\hline Margin revisions before consensus guideline implementation & $54(23.6)$ \\
\hline Margin revisions after consensus guideline implementation & $20(18.0)$ \\
\hline Completion mastectomy & $16(4.7)$ \\
\hline Positive margins & $32(9.4)$ \\
\hline
\end{tabular}

Table 4. Postoperative complications

\begin{tabular}{|lc|}
\hline Complication & No. (\%) \\
\hline Abscess needing intervention & $1(0.2)$ \\
\hline Hematoma needing intervention & $10(2.9)$ \\
\hline Seroma needing intervention & $6(1.8)$ \\
\hline SSI/wound complication needing intervention & $13(3.8)$ \\
\hline SSI = surgical site infection. & \\
\hline
\end{tabular}

The BreastQ questionnaire, designed and validated by Pusic and colleagues, ${ }^{21}$ explores satisfaction with breasts, process of care, and psychosocial, physical and sexual well-being. By studying these individual and at times deeply personal aspects of a patient's relationship with their breasts, the surgical community has the potential to promote patient advocacy and build an evidence-based approach to practice.

Patients in this series served as their own control, comparing PROMs before surgery with those 9 months after surgery. Patients in our study were highly satisfied with their breast outcomes after surgery, with higher BreastQ scores for breast satisfaction 9 months after surgery than at baseline. The BreastQ scores for physical well-being were higher 9 months postoperatively than preoperatively, but lower than scores at 3 months

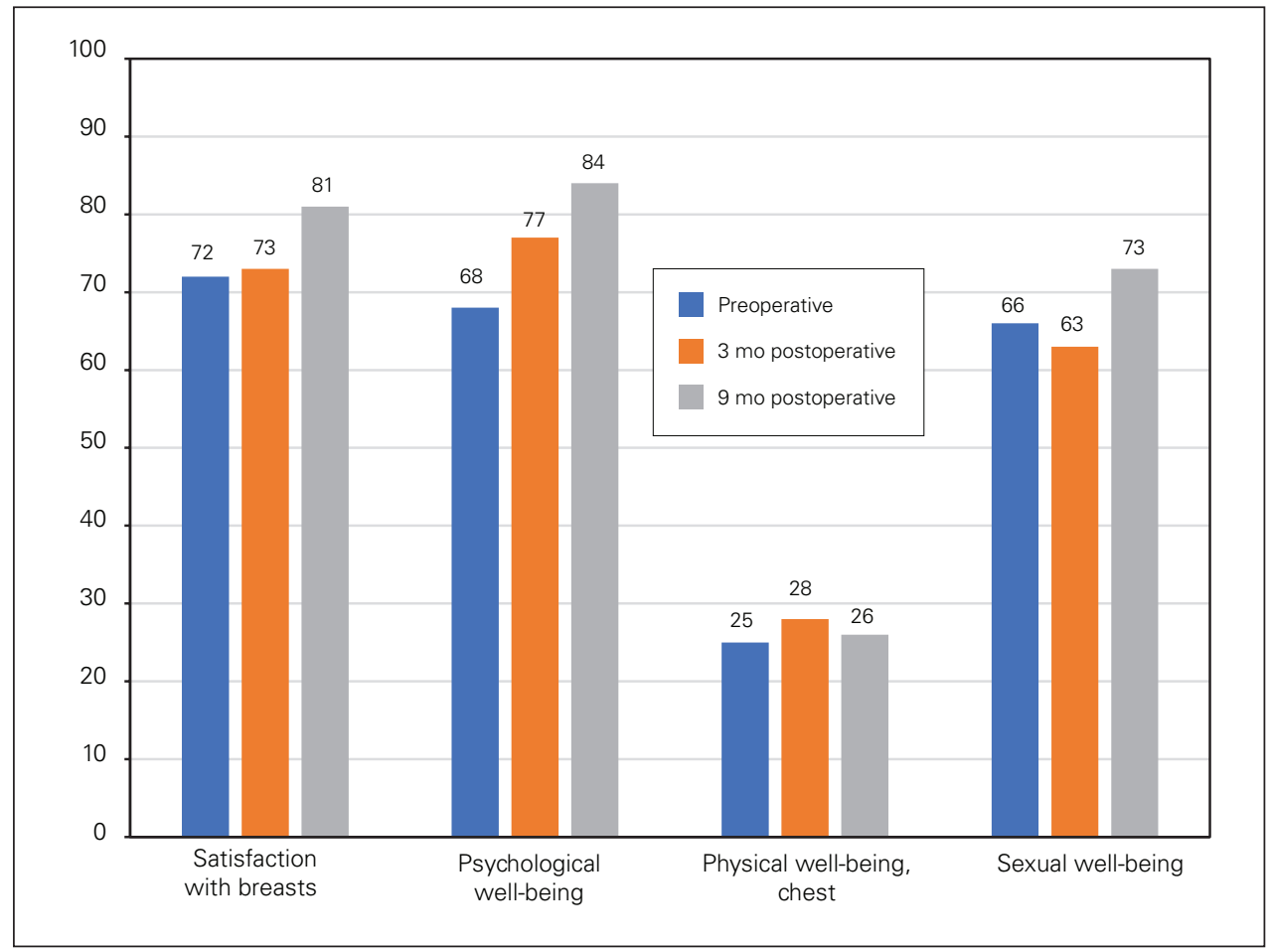

Fig. 3. Average BreastQ rasch scores for each domain preoperatively and at 3 and 9 months postoperatively.

breast cancer diagnosis, cosmetic outcomes, which have been shown to contribute greatly to long-term quality of life, are also becoming increasingly important. Previous studies have shown that OPBS can have superior cosmetic outcomes to conventional surgery. ${ }^{3,5,6,10}$ Studies analyzing cosmetic outcomes can at times rely on assessment by an expert panel of breast surgeons, plastic surgeons, specialist nurses and medical students among others, and can therefore introduce an element of observer bias. Using Patient Reported Outcome Measures (PROMs) questionnaires, however, enables a more direct measurement of long-term patient satisfaction. postsurgery. We postulate that the decrease in this specific quality of life metric between 3 and 9 months after surgery is a reflection of the adverse effects of radiotherapy - namely radiation-induced chest wall tenderness - rather than a complication of OPBS itself. Despite our study not having a control group, the PROMs scores in our oncoplastic cohort were superior to those in patients receiving traditional breast-conserving surgery in a retrospective review by Flanagan and colleagues. ${ }^{22}$ This analysis of more than 3000 women from a prospectively maintained database compared BreastQ outcomes of patients undergoing conventional 
A

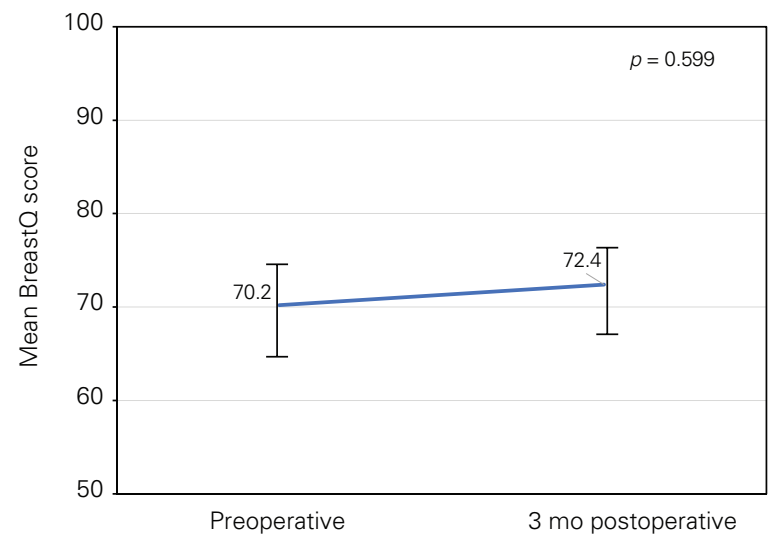

C

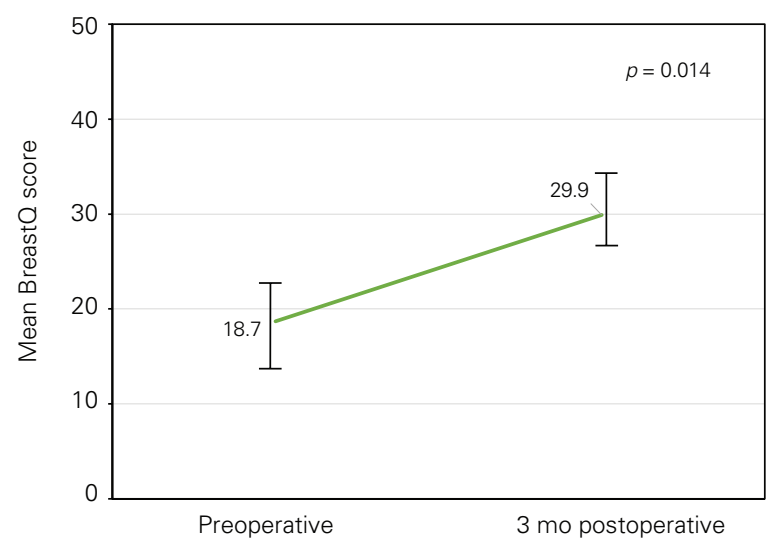

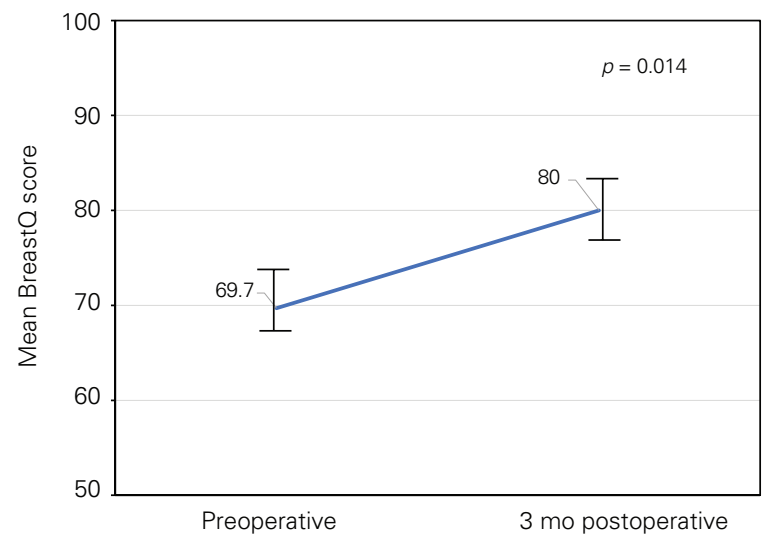

D

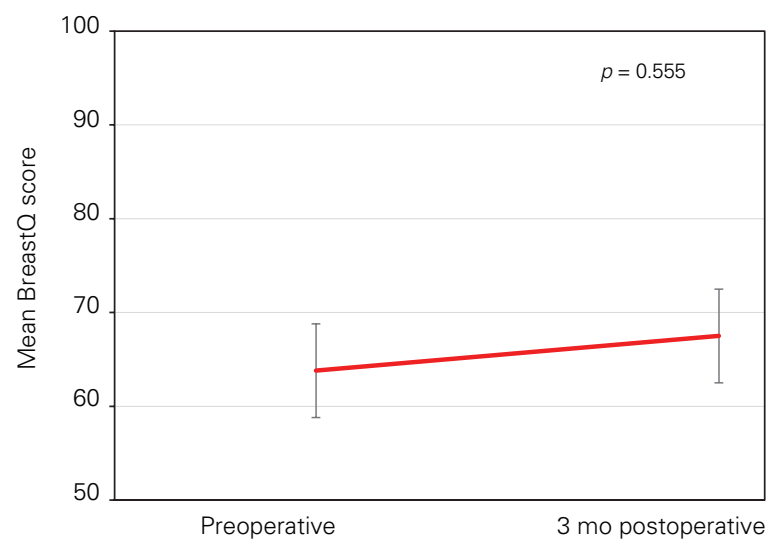

Fig. 4. Average BreastQ rasch scores for (A) satisfaction with breasts; (B) psychosocial well-being; (C) physical well-being, chest; and (D) sexual well-being preoperatively and 3 months postoperatively, compared using a paired $t$ test. Standard error bars included.

breast-conserving surgery to those of patients undergoing a mastectomy with IBR. Although BreastQ scores were better in the former cohort, they increased over time in the psychosocial well-being and sexual wellbeing domains in both groups, much like the BreastQ scores in our series. Unlike in our study, however, scores for breast satisfaction after traditional breast conservation surgery were seen to decrease over time. Patients in our series reported a short- and long-term improvement after undergoing oncoplastic surgery. This further supports previous studies showing that patient satisfaction is highest in patients undergoing OPBS than traditional breast-conserving surgery, which is in turn better than patient-reported outcomes in women undergoing mastectomy with IBR and PROMs in patients undergoing mastectomy without breast reconstruction. ${ }^{6}$ Therefore, although our study does not directly compare BreastQ scores of patients undergoing OPBS with scores of patients undergoing mastectomy with IBR, comparison with quality of life data from the study by Flanagan and colleagues suggests that patients receiving OPBS would have improved PROMs scores compared with those receiving mastectomy with IBR.

A similar series from Ontario describes a single surgeon's OPBS practice in a community hospital setting. ${ }^{4}$ This series, describing a similar population to that in our study, looked at clinical as well as oncological outcomes and confirmed a locoregional recurrence risk of $3.3 \%$ at a median of 18 months' follow-up. Although the study period in our series is arguably too short to observe any meaningful long-term oncological outcomes, our data collection is ongoing. It will be most interesting to observe the rate of local failure in patients undergoing so-called "extreme oncoplastics" (i.e., patients who would historically have been advised to undergo a mastectomy with possible post-mastectomy radiotherapy; for example, those with tumours larger than $5 \mathrm{~cm}$, multicentric tumours with positive axillary lymph nodes, and large areas of in situ disease excised to a clear margin). ${ }^{23,24}$ Furthermore, there is a growing body of literature confirming that the improved cosmetic outcomes seen as a result of OPBS do not compromise oncological 


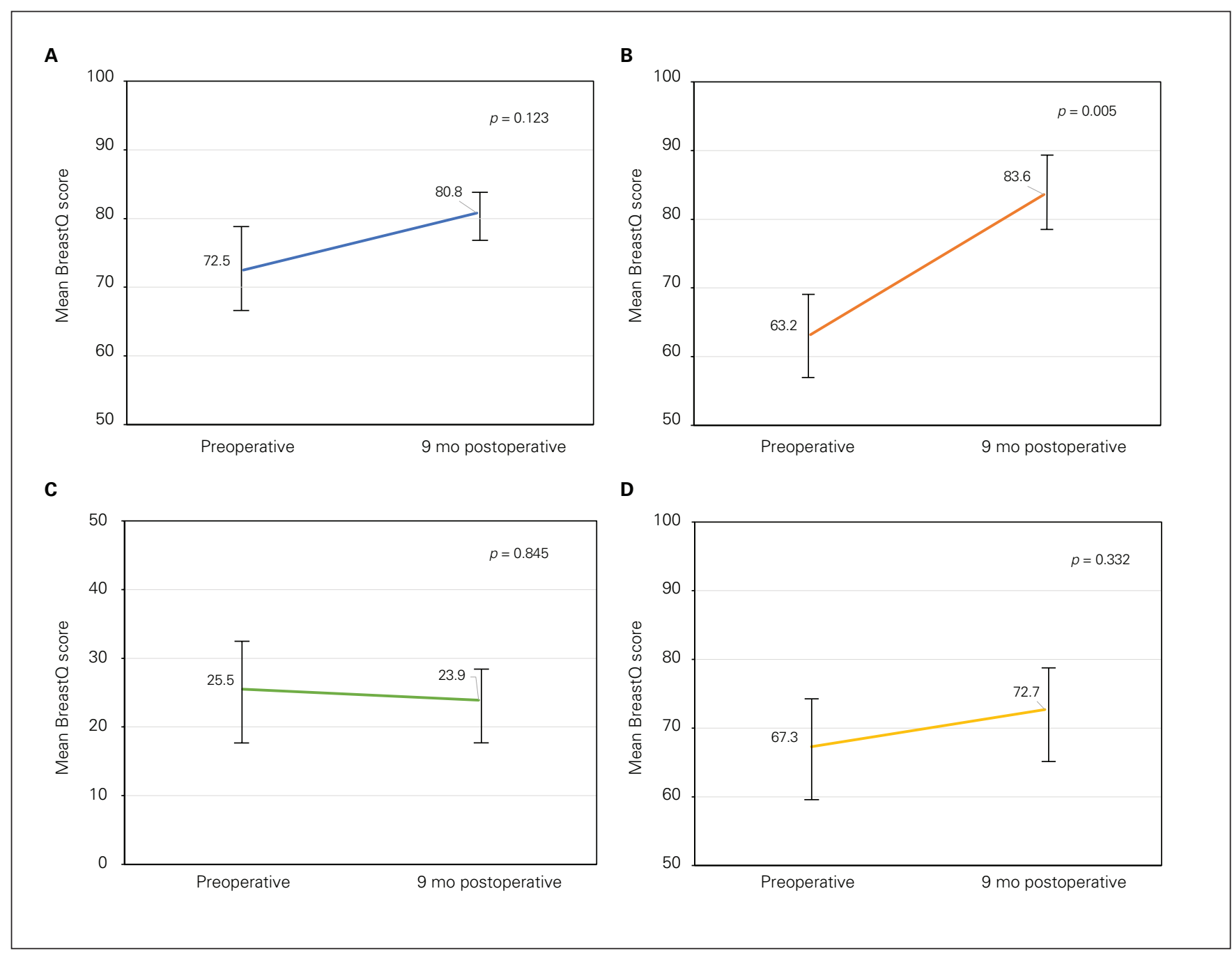

Fig. 5. Average BreastQ rasch scores for (A) satisfaction with breasts; (B) psychosocial well-being; (C) physical well-being, chest; and (D) sexual well-being preoperatively and 9 months postoperatively, compared using a paired $t$ test. Standard error bars included.

outcomes. ${ }^{3,4}$ Knowles and colleagues found a delay to adjuvant therapy due to postoperative complications occurred in only $3.2 \%$ of patients undergoing OPBS. ${ }^{4}$ Local and distant recurrences occurred in $3.3 \%$ and $0.7 \%$ patients, respectively, with an overall survival of $99.3 \% .{ }^{4}$ Clough and colleagues found similar results, with a delay in adjuvant therapy occurring in $5 \%$ of patients, a local recurrence rate of $9.4 \%$, and an overall survival rate of $95.7 \% .^{3}$ Although our study did not look at local recurrence rates, we did analyze positive margin status. The overall positive margin status was $9.4 \%$. The revision margin rate was $18 \%$ after updated margin recommendations were implemented in late 2018. This rate is consistent with those reported in other studies looking at margin revision rates after OPBS, which range from $12 \%$ to $16 \% .4,8$ This once again compares favourably to the positive margin status after traditional breastconserving surgery, which has previously been shown to be between $15 \%$ and $47 \% .25,26$
The average cup size of patients in our series was a C-cup, and the average lesion size in our study was $1.8 \mathrm{~cm}$, with 10 patients having lesions larger than $5 \mathrm{~cm}$. Our findings are in keeping with those of previous oncoplastic series, which reported an average lesion size of $1.7 \mathrm{~cm}-2.6 \mathrm{~cm} .{ }^{3,4}$ When counselling patients on their surgical options, lesion size should not be the primary decision-making factor when choosing between a mastectomy or breast conservation; 10 patients in our series underwent OPBS for T3 tumours. Volume replacement surgery (e.g., using a latissimus dorsi "mini-flap" or a chest wall perforator flap) enables large-volume resections in smaller breasts without leaving a significant defect and resulting breast distortion, which can then be worsened by radiation treatment. Given the diverse range of procedures aimed at maintaining breast symmetry, our series shows that with appropriate counselling, the choice to have breast-conserving surgery or to undergo a mastectomy should be based primarily on 
patient preference rather than the worry of a cosmetic penalty in striving to achieve clear margins.

One of the main advantages of breast-conserving surgery, traditional or oncoplastic, is the opportunity to avoid the long-term physical and psychosocial effects of a mastectomy. Oncoplastic breast surgery reduces mastectomy rates by allowing for larger resections while still conserving the breast. Our completion mastectomy rate was $4.7 \%$. This was lower than the average completion mastectomy rate of $6.5 \%$ reported in a meta-analysis by Losken and colleagues. ${ }^{10}$ Of the patients receiving a completion mastectomy in our series, 5 patients were able to receive immediate reconstruction by the same surgeon performing a mastectomy, avoiding the need to coordinate with a separate reconstructive surgeon, allowing more women to access breast reconstruction in a timely fashion. ${ }^{27}$

Twenty-five patients received contralateral symmetrizing procedures by the same oncoplastic surgeon. Most of these operations took place at the same time as the contralateral oncological operation in order to achieve symmetry at the index operation, to avoid the need for a second surgery and to free up valuable operating room capacity. A contralateral procedure rate of $9 \%$ is lower than often reported in the literature. In our study, most patients underwent a contralateral symmetrizing procedure as part of a wise pattern therapeutic reduction mammoplasty. The significant volume reduction associated with this surgery mandates a "balancing" operation that can be done at the same time or delayed until the completion of adjuvant treatments. Patients undergoing non-Wise-pattern mammoplasties (medial/ lateral/V-mammoplasties) did not have balancing surgery performed at the same time, as the volume loss (and therefore asymmetry) was deemed to be less likely to need symmetrizing surgery at the time of the oncological operation. This low contralateral procedure rate also highlights that level I oncoplastic resections provide improved cosmetic outcomes and lower mastectomy rates, which we postulate reduce the need for a contralateral procedure.

\section{Limitations}

One of the main drawbacks of our study was the lack of a control group of patients undergoing traditional breastconserving surgery. All the patients in our series underwent OPBS performed by a single surgeon who routinely uses level I OPBS as a standard of care. Breast surgeons within our surgical group who are not trained in OPBS consented to having their patients entered into this study, and prospective selection of non-OPBS patients matched to the OPBS cohort will be deferred to a future analysis.

Another limitation related to the PROMs data collection was the relatively small number of patients who completed the BreastQ questionnaire. These surveys were administered exclusively to patients who underwent level II oncoplastic procedures, and data collection was introduced into the surgeon's practice only near the end of our study period. For this reason, and to address our lack of a control group, we plan to continue to prospectively collect BreastQ data and expand this analysis to include mastectomy (matched to patients undergoing "extreme OPBS" for T3 tumours) as well as patients undergoing traditional breast-conserving surgery. Drawing more on patient-reported satisfaction outcomes combined with the prospective collection of clinical outcome data will help us further highlight the benefits of OPBS.

A further potential drawback of any PROMs study is the bias introduced when patients know that their surgeon is collecting their outcome data. As a result, there may be a tendency for patients to inflate their outcomes while downplaying their dissatisfaction. To counteract this potential source of bias, questionnaires were anonymized from the outset when given to patients, with no identifying labels on each BreastQ questionnaire. Furthermore, the anonymized questionnaire was not returned to the treating surgeon, but to the surgeon's office in a sealed envelope.

\section{Conclusion}

Oncoplastic breast surgery has the potential to offer patients superior cosmetic results and, therefore, improved patient-reported outcomes. This series of patients undergoing both level I and II OPBS is, to our knowledge, the first of its kind in Canada to analyze not only clinical outcomes, but also patient-reported outcome measures. We hope that this will help to drive the recruitment of surgeons trained in oncoplastic procedures to both teaching and community hospitals in order to enable these techniques to become the standard of care in North America.

Affiliations: From the University of Alberta, Faculty of Medicine and Dentistry, Edmonton, Alta. (DiPasquale, Prus-Czarnecka, Delmar, Peiris); the Department of Surgery, University of Alberta, Edmonton, Alta. (DiPasquale, Peiris); and Covenant Health, Misericordia Community Hospital, Edmonton, Alta. (Peiris).

Competing interests: None declared.

Contributors: A. DiPasquale and L. Peiris designed the study. A. DiPasquale, L. Delmar and L. Peiris acquired the data, which A. DiPasquale, Z. Prus-Czarnecka and L. Peiris analyzed. A. DiPasquale, Z. Prus-Czarnecka and L. Peiris wrote the article, which all authors reviewed. All authors gave final approval of the article to be published.

Content licence: This is an Open Access article distributed in accordance with the terms of the Creative Commons Attribution (CC BYNC-ND 4.0) licence, which permits use, distribution and reproduction in any medium, provided that the original publication is properly cited, the use is noncommercial (i.e., research or educational use), and no modifications or adaptations are made. See: https://creativecommons. org/licenses/by-nc-nd/4.0/ 


\section{References}

1. Macmillan RD, McCulley SJ. Oncoplastic breast surgery: What, when and for whom? Curr Breast Cancer Rep 2016;8:112-7.

2. Chatterjee A, Gass J, Patel K, et al. A consensus definition and classification system of oncoplastic surgery developed by the American Society of Breast Surgeons. Ann Surg Oncol 2019;26:3436-44.

3. Clough KB, Lewis J, Couturaud B, et al. Oncoplastic techniques allow extensive resections for breast-conserving therapy of breast carcinoma. Ann Surg 2003;237:26-34.

4. Knowles S, Maxwell J, Lumsden A, et al. An alternative to standard lumpectomy: a 5-year case series review of oncoplastic breast surgery outcomes in a Canadian setting. Can 7 Surg 2020;63:E46-51.

5. Gendy RK, Able J, Rainsbury R. Impact of skin-sparing mastectomy with immediate reconstruction and breast-sparing reconstruction with miniflaps on the outcomes of oncoplastic surgery. Br 7 Surg 2003;90:433-9.

6. Chand ND, Browne V, Paramanathan N, et al. Patient-reported outcomes are better after oncoplastic breast conservation than after mastectomy and autologous. Plast Reconstr Surg Glob Open 2017;5:E1419.

7. Nano MT, Gill PG, Kollias J, et al. Breast volume replacement using the latissimus dorsi miniflap. ANZ 7 Surg 2004;74:98-104.

8. Asgeirsson KS, Rasheed T, McCulley SJ, et al. Oncological and cosmetic outcomes of oncoplastic breast conserving surgery. EFSO 2005;31:817-23.

9. Mansell, J, Weiler-Mithoff, E, Stallard, S et al. Oncoplastic breast conservation surgery is oncologically safe when compared to wide local excision and mastectomy. Breast 2017;32:179-185.

10. Losken A, Dugal C, Styblo T, et al. A meta-analysis comparing breast conservation therapy alone to the oncoplastic technique. Ann Plast Surg 2014;72:145-9.

11. Rainsbury D, Willett A, editors. BAPRAS (2015) Oncoplastic breast reconstruction: guidelines for best practice. London: British Association of Plastic Reconstructive and Aesthetic Surgeons; 2015.

12. Jeevan R, Cromwell D, Browne J, et al. National mastectomy and breast reconstruction audit 2011. NHS Information Centre; 2011.

13. Baxter N, Goel V, Semple J. Utilization and regional variation of breast reconstruction in Canada. Plast Reconstr Surg 2005;115:338-9.

14. Platt J, Zhong T, Moineddin R, et al. Geographic variation immediate and delayed breast reconstruction utilization in Ontario, Canada and plastic surgeon availability: a population- based observational study. World f Surg 2015;39:1909-21.
15. Porter G, Wagar B, Bryant $\mathrm{H}$, et al. Rates of breast cancer surgery in Canada from 2007/08 to 2009/10: retrospective cohort study. CMAf Open 2014;2:E102-8.

16. Maxwell J, Roberts A, Cil T, et al. Current practices and barriers to the integration of oncoplastic breast surgery: a Canadian perspective. Ann Surg Oncol 2016;23:3259-65.

17. Consensus Guideline on Breast Cancer Lumpectomy Margins. Columbia (MD): American society of breast surgeons; 2018.

18. Memorial Sloan Kettering Cancer. BreastQ Users' Manual Version 2.0.; 2015. Available: https://www.rcseng.ac.uk/-/media/files/rcs/ standards-and-research/standards-and-policy/service- standards/ cosmetic-surgery/datasets/breastq-user-manual-2015.pdf (accessed 2020 Oct. 10)

19. Vitug AF, Newman L. Complications in breast surgery. Surg Clin North Am 2007;87:431-51.

20. De La Cruz L, Blankenship S, Chatterjee A, et al. Outomes after oncoplastic breast-conserving surgery in breast cancer patients: a systematic literature review. Ann Surg Oncol 2016;23:3247-58.

21. Pusic AL, Klassen AF, Scott AM, et al. Development of a new patient- reported outcome measure for breast surgery: the BREASTQ. Plast Reconstr Surg 2009;124:345-53.

22. Flanagan MR, Zabor E, Romanoff A, et al. A comparison of patient-reported outcomes after breast-conserving surgery and mastectomy with implant breast reconstruction. Ann Surg Oncol 2019;26:3133-40.

23. Silverstein MJ, Savalia N, Khan S, et al. Extreme oncoplasty: breast conservation for patients who need mastectomy. Breast $\mathcal{f}$ 2015;21:52-9.

24. Pearce BC, Fiddes R, Paramanathan N, et al. Extreme oncoplastic conservation is a safe new alternative to mastectomy. Eur $\mathcal{F}$ Surg Oncol 2020;46:71-6.

25. Lovrics PJ, Cornacchi SD, Farrokhyar F, et al. The relationship between surgical factors and margin status after breast-conservation surgery for early-stage breast cancer. Am 7 Surg 2009;197: 740-6.

26. Pleijhuis RG, Graafland M, de Vries J, et al. Obtaining adequate surgical margins in breast-conserving therapy for patients with earlystage breast cancer: current modalities and future directions. Ann Surg Oncol 2009;16:2717-30.

27. Peiris L, Olson D, Kelly D. Oncoplastic and reconstructive breast surgery in Canada: breaking new ground in general surgical training. Can F Surg 2018;61:294-9. 